\title{
SALA DE AULA COMENTADA: UM DVD PARA O PROFESSOR DE INGLÊS FOMENTAR SEU CONHECIMENTO PEDAGÓGICO ${ }^{1}$
}

\author{
Rosely Perez XAVIER \\ Pós-Graduação em Linguística - Universidade Federal de Santa Catarina
}

\begin{abstract}
RESUMO: O presente artigo descreve as bases teóricas e metodológicas utilizadas para a criação de um DVD educativo, produzido para suscitar reflexão do professor de inglês sobre determinadas situações de sala de aula e fomentar seu conhecimento pedagógico. A mídia consiste em oito fragmentos de aulas de língua inglesa conduzidas em diferentes turmas do ensino fundamental e médio no contexto de escolas públicas. São reproduções de eventos reais de sala de aula disponibilizados em animação $2 \mathrm{D}$, visando preservar o anonimato dos professores e alunos envolvidos, e comentados por duas especialistas que atuam nas áreas de Formação de Professores de Língua Inglesa e de Ensino-Aprendizagem de Língua Estrangeira da Universidade Federal de Santa Catarina. A concepção de aprendizagem docente norteadora é apresentada, assim como as escolhas e justificativas tomadas no processo de decisão sobre o recorte das aulas transcritas e a sua análise no DVD.

PALAVRAS-CHAVE: DVD educativo; formação continuada de professores; língua inglesa
\end{abstract}

\begin{abstract}
This article describes the theoretical and methodological bases underlying an educational DVD that was produced to promote English teachers' reflection on classroom events, with the ultimate goal of fostering their pedagogical knowledge. The media consists of eight English lesson fragments that were conducted in different groups of students at public schools of basic education. These fragments come from genuine classroom situations that were animated in $2 D$ to preserve the anonymity of the real teachers and students and commented by two specialists on English teacher education and foreign language teaching and learning from Universidade Federal de Santa Catarina. The teaching learning conception that guides the media is presented, as well as the choices and justifications made during the decision-making process for the lesson cutouts and their analyses.
\end{abstract}

KEYWORDS: educational DVD; continuing teacher education; English language

\section{Introdução}

O desenvolvimento profissional docente é um processo contínuo que conta com as experiências práticas do professor, seu planejamento, conselhos ou dicas de colegas professores, cursos de formação continuada, palestras, seminários, leituras na área, recursos tecnológicos digitais, entre outras possibilidades. Para o professor de língua estrangeira, tais possibilidades o ajudam a aprimorar seu trabalho, ampliando seu conhecimento pedagógico e o seu conhecimento (e competência) linguístico-comunicativo na língua-alvo.

Dentre as possibilidades de aprimoramento profissional, os recursos tecnológicos parecem estar à mão dos professores mais facilmente, em particular do professor de língua estrangeira

\footnotetext{
${ }^{1}$ Este trabalho é resultado do Projeto Institucional de Formação de Professores de Inglês do Estado de Santa Catarina - Universidade Federal de Santa Catarina, financiado pela SEB-MEC e coordenado pelas professoras Rosely P. Xavier e Adriana K. Dellagnelo, no período entre agosto/2013 e março/2015.
} 
(inglês), que ao acessar a internet poderá encontrar inúmeros sites e vídeos para desenvolver seu conhecimento pedagógico e linguístico-comunicativo.

Considerando o desenvolvimento pedagógico do professor de inglês, muitos vídeos ainda se limitam a dar dicas, ideias e estratégias de como melhorar a prática docente sem necessariamente partir da ação situada, do contexto real de interação e intersubjetividade construído entre professor e alunos em sala de aula. Sabemos que as práticas pedagógicas são singulares, embora possam ter, eventualmente, convergências. Por essa razão, é importante partir da realidade local do professor, de seu próprio contexto de trabalho, para criarmos possibilidades para o seu desenvolvimento profissional contínuo.

O presente artigo tem como objetivo apresentar as bases teóricas e metodológicas utilizadas para a criação de um DVD educativo, que foi produzido a partir de eventos reais de sala de aula, de realidades situadas de ensino e aprendizagem para suscitar a reflexão do professor de inglês sobre determinadas situações de interação presentes na sala de aula de língua estrangeira. O objetivo da mídia é fomentar o conhecimento pedagógico do professor de inglês e, consequentemente, contribuir com o seu desenvolvimento profissional.

$\mathrm{O}$ artigo é dividido em quatro seções. Na primeira, contextualizo a gênese da mídia e, na seção seguinte, apresento a noção de conhecimento pedagógico defendida neste trabalho. Ainda que brevemente, discuto também as possibilidades de aprimoramento docente com a ajuda das tecnologias audiovisuais (vídeos). A terceira seção discorre sobre a construção do DVD, explicando os critérios adotados para a seleção dos fragmentos de aulas e a sua análise. $\mathrm{Na}$ sequência, abordo a concepção de aprendizagem docente que orientou a produção da mídia. $\mathrm{O}$ artigo finaliza com as conclusões.

\section{Contextualizando a mídia}

A produção de um DVD educativo foi uma das metas do Projeto Institucional de Formação Continuada de Professores de Inglês de Santa Catarina, financiado pela SEB-MEC e coordenado pelas professoras doutoras Rosely P. Xavier e Adriana Kuerten Dellagnelo da Universidade Federal de Santa Catarina (UFSC), no período de agosto de 2013 a março de 2015. O projeto compreendeu uma série de ações, com as seguintes metas:

a) O oferecimento de dois módulos de ensino a distância pela Plataforma Moodle UFSC, prioritariamente para professores efetivos de inglês de Santa Catarina atuando em escolas que haviam aderido à época aos Programas Ensino Médio Inovador² e Mais Educação ${ }^{3}$.

\footnotetext{
${ }^{2}$ ProEMI é um programa do governo federal que busca garantir a formação integral do estudante do ensino médio, o que implica um redesenho dos currículos para oferecer atividades que possam promover a educação científica e humanística, a valorização da leitura, da cultura, entre outras. Para essa modificação curricular, as escolas do Estado de Santa Catarina, que aderiram a esse programa, aumentaram a carga horária da disciplina de língua inglesa de duas para cinco horas semanais nos três anos do ensino médio.

3 O Programa Mais Educação visa à ampliação da jornada escolar do estudante do ensino fundamental e a organização curricular na perspectiva da Educação Integral, por meio do oferecimento de atividades nos campos de artes, cultura, esporte e lazer, mediante a complementação da carga horária de cinco ou quinze horas semanais no turno e contraturno escolar (http://portal.mec.gov.br/programa-mais-educacao).
} 
O primeiro módulo foi sobre materiais de ensino de língua inglesa, cujo objetivo foi promover o aprimoramento metodológico dos professores por meio da análise, avaliação, adaptação e produção de atividades de ensino e aprendizagem de inglês. $O$ curso teve início em agosto/2013 e término em dezembro/2013 com carga horária total de 90 horas em 15 semanas de trabalho online.

O segundo módulo foi sobre o uso da língua estrangeira para a sala de aula e teve como objetivo desenvolver a competência comunicativa do professor, de modo a incidir sobre a sua interação com os alunos em sala de aula nessa língua. O curso teve início em março/2014 e término em junho/2014 com carga horária total de 90 horas em 15 semanas de trabalho online.

Para cada um desses módulos, 160 vagas foram ofertadas para professores das escolas estaduais de Santa Catarina.

b) Outra meta do projeto foi a produção do livro Themes for Teaching English - Vol. 2, que apresenta seis unidades temáticas: Advertisement, Behavior, Body Image, Humor, Music e Travel, cada qual explorada por um conjunto de atividades de ensino-aprendizagem de natureza comunicativa. As atividades do livro foram elaboradas por alunos de Estágio Supervisionado de Inglês da UFSC e por bolsistas do PIBID - Inglês sob a orientação da autora deste artigo. O objetivo do livro foi proporcionar gratuitamente aos professores de inglês do estado de Santa Catarina recurso pedagógico adicional para as suas aulas. A versão ebook pode ser acessada pelos endereços: www.t4tenglish.ufsc.br e pibidinglesufsc.blogspot.com.br, assim como todo o material autovisual.

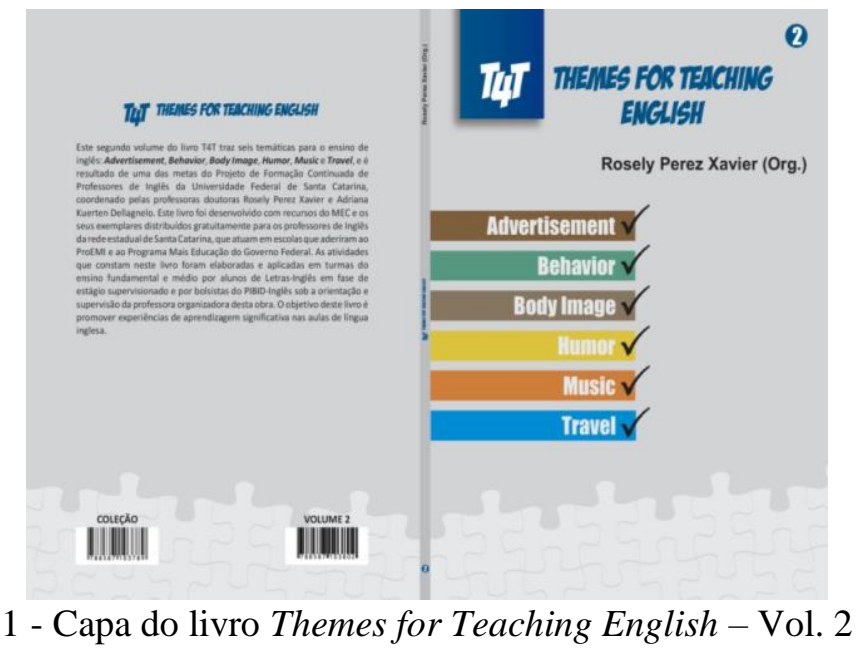

c) A terceira e última meta foi a produção do DVD Sala de Aula comentada, foco deste trabalho. A ideia de produzir esse DVD foi inspirada no Programa de TV britânica Supernanny, em que uma babá muito especial é solicitada por algumas famílias a ajudá-las a melhorar o comportamento social de seus filhos e, assim, promover harmonia no convívio familiar. Para isso, a babá frequenta a casa da família para observar e analisar o 
comportamento da(s) criança(s) e dos pais para depois relatar a eles as possíveis causas da desarmonia familiar.

Com base nesse programa de TV, surgiu a vontade de levar essa ideia para o contexto de sala de aula de inglês da escola básica, não para tratar da disciplina/ indisciplina dos alunos, mas para possibilitar ao professor dessa língua visualizações de certas práticas que podem ou não favorecer a aprendizagem significativa, considerando uma análise feita por profissionais que trabalham com formação inicial e continuada de professores. Dessa forma, o DVD foi produzido para promover reflexão do professor de inglês sobre as ações desse profissional na interação com seus alunos, partindo de situações reais de sala de aula e, assim, gerar (a) conhecimento pedagógico, (b) conhecimento sobre formas de maximizar a aprendizagem dos alunos e (c) conhecimento sobre a língua-alvo.

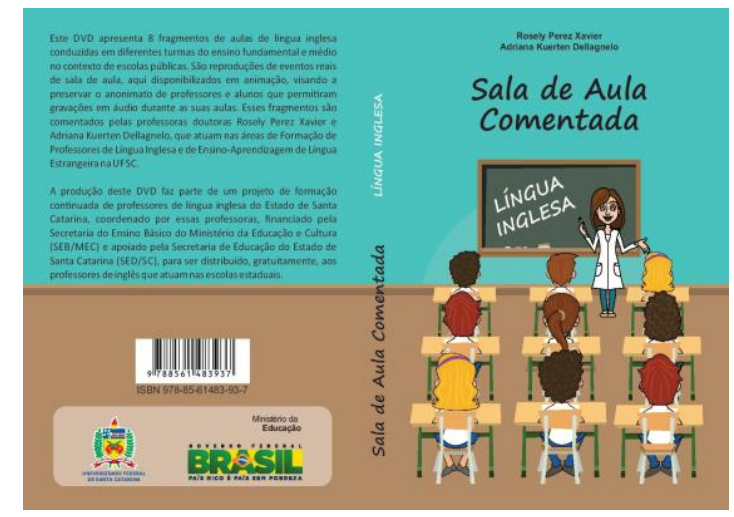

2 - Capa do DVD Sala de Aula Comentada

\section{O desenvolvimento pedagógico do professor}

Segundo Gatconton (1999, p. 35), o conhecimento pedagógico é "o conhecimento acumulado do professor sobre o ato de ensinar (i.e., seus objetivos, procedimentos, estratégias), que serve como base para o seu comportamento em sala de aula e suas atividades de ensinoaprendizagem”.

Sabemos que o conhecimento pedagógico do professor é dinâmico, pois se desenvolve em processo contínuo, muitas vezes com a ajuda de tecnologias audiovisuais e telemáticas. A internet, por exemplo, disponibiliza inúmeros vídeos que podem (ou não) ter algum impacto direto na prática pedagógica do professor. Se fizermos uma busca no ambiente virtual, podemos encontrar diferentes tipos de vídeos. Os how-to vídeos, por exemplo, visam a dar dicas, ideias e estratégias de ensino consideradas efetivas sob a perspectiva do produtor da mídia $^{4}$, que, muitas vezes, não é formador de professores. São vídeos sobre como ensinar inglês para adultos/ crianças, como ensinar com diversão, como ensinar o present perfect e etc. $\mathrm{O}$ professor que consume esses vídeos busca conhecimento metodológico.

\footnotetext{
${ }^{4}$ Exemplos: https://www.youtube.com/watch?v=OHjLXDStilo; https://www.youtube.com/watch?v=-nqBKrNo_U.
} 
No ambiente virtual também encontramos videoaulas e videocursos com professores nativos e não nativos, que ensinam a língua estrangeira. ${ }^{5} \mathrm{O}$ professor que consome esses vídeos busca conhecimento linguístico-comunicativo, podendo eventualmente transferir a maneira como a mídia abordou o assunto para o seu contexto de sala de aula. Diante dessas mídias, o professor geralmente se vê no papel de aluno.

Há ainda os chamados 'vídeos de sala de aula' que retratam a interação entre professor e aluno(s) com o objetivo de mostrar uma aula genuína de língua estrangeira ${ }^{6}$. Não são exatamente produções que buscam teorizar a prática docente, tampouco trazem uma leitura metodológica/ pedagógica crítica sobre a aula. Nesse sentido, esses vídeos pouco contribuem com a aprendizagem docente.

Foi pensando no desenvolvimento profissional do professor de inglês que o DVD Sala de aula comentada foi produzido, numa perspectiva que pudesse relacionar a prática pedagógica situada desse professor e a teoria que dela resulta.

\section{A descrição da mídia}

O DVD apresenta oito fragmentos de aulas de língua inglesa que foram conduzidas em diferentes turmas do ensino fundamental e médio de escolas públicas, e disponibilizados em animação 2D para preservar o anonimato dos professores e alunos envolvidos nas gravações de sala de aula.

Cada fragmento tem entre 50 segundos e 2 minutos de duração. Após cada fragmento, alguns aspectos da aula são comentados por professoras especialistas nas áreas de Formação de Professores de Língua Inglesa e de Ensino-Aprendizagem de Língua Estrangeira da UFSC. O DVD completo tem aproximadamente 60 minutos de duração.

Para trazer o contexto real de sala de aula para o DVD, seis alunos da disciplina Metodologia do Ensino de Inglês do Curso de Letras-Inglês da UFSC (semestre 2014/1) desenvolveram individualmente, sob a orientação da autora deste artigo, três planos de aula com atividades de ensino e aprendizagem para serem aplicados no Estágio Supervisionado I, em uma turma do ensino fundamental ou médio. No total, foram desenvolvidos 18 planos de aula e 17 atividades de ensino-aprendizagem sobre as seguintes temáticas:

Elections (6 planos; 7 atividades) - Dupla 1

Pets (6 planos; 5 atividades) - Dupla 2

Job (6 planos; 5 atividades) - Dupla 3

\footnotetext{
5 Exemplos:

https://www.youtube.com/watch?v=R49zGknt7EE.

Exemplos:
https://www.youtube.com/watch? $=$ mGB83yxUB_U.
}

https://www.youtube.com/watch?v=aP1MtU5p3So;

https://www.youtube.com/watch?v=qLCbblQHBp8; 
Na disciplina de Estágio Supervisionado I, cada estagiário:

a) conduziu três horas-aula em uma turma do ensino fundamental ou médio de uma escola pública, utilizando o material didático que havia elaborado na disciplina de metodologia de ensino;

b) gravou suas aulas em áudio com equipamento de microfone de lapela, disponibilizado pela coordenação do projeto;

c) transcreveu suas aulas para subsidiá-lo em seus relatos de autoavaliação e para constituir scripts para as falas de professor e alunos no DVD. Os estagiários estavam cientes de que os scripts iriam ser utilizados para a produção de um DVD, isto é, para os cenários animados de sala de aula com as falas de professor e alunos articuladas em animação. Sabiam também que as animações iriam receber vozes de outras pessoas. As locuções foram feitas em estúdio com termo assinado de consentimento de voz. No total, foram 18 aulas gravadas em áudio e transcritas.

d) assistiu às três aulas do colega de equipe para fazer anotações das falas dos alunos e assim ajudar o colega no momento das transcrições.

As transcrições das aulas foram analisadas pelas professoras autoras do DVD para a seleção de oito eventos de interação. Essa seleção se baseou nos procedimentos de ensino considerados positivos e negativos na perspectiva dessas professoras. Os eventos escolhidos ilustram, portanto, diferentes momentos de interação do professor estagiário com seus alunos, como especificado no quadro a seguir:

\begin{tabular}{|c|c|c|c|}
\hline & Eventos interativos e seus conteúdos & Tema & Turma \\
\hline Fragmento 1 & $\begin{array}{l}\text { Conversa em inglês entre professora e } \\
\text { alunos sobre animais de estimação } \\
\text { (What pet do you have?). }\end{array}$ & Pets & $\begin{array}{l}6^{\circ} \text { ano } \\
\text { do ensino fundamental }\end{array}$ \\
\hline Fragmento 2 & $\begin{array}{l}\text { Explicação da professora sobre o que } \\
\text { os alunos devem fazer na atividade e } \\
\text { seus questionamentos para verificar a } \\
\text { compreensão da classe. }\end{array}$ & Pets & $\begin{array}{l}6^{\circ} \text { ano } \\
\text { do ensino fundamental }\end{array}$ \\
\hline Fragmento 3 & $\begin{array}{l}\text { Condução de uma atividade de leitura } \\
\text { e sua correção. A atividade requer a } \\
\text { compreensão de um e-mail de um } \\
\text { candidato que se interessou por um } \\
\text { anúncio de emprego. }\end{array}$ & $J o b$ & $\begin{array}{l}2^{\circ} \text { ano } \\
\text { do ensino médio }\end{array}$ \\
\hline
\end{tabular}




\begin{tabular}{|c|c|c|c|}
\hline Fragmento 4 & $\begin{array}{l}\text { Conversa em inglês entre professora e } \\
\text { alunos sobre animais de estimação } \\
\text { (What do you do when you see } \\
\text { somebody treating an animal badly?). }\end{array}$ & Pets & $\begin{array}{l}6^{\circ} \text { ano } \\
\text { do ensino fundamental }\end{array}$ \\
\hline Fragmento 5 & $\begin{array}{l}\text { Conversa em inglês entre professora e } \\
\text { alunos sobre animais de estimação } \\
\text { (What do pets need?). }\end{array}$ & Pets & $\begin{array}{l}6^{\circ} \text { ano } \\
\text { do ensino fundamental }\end{array}$ \\
\hline Fragmento 6 & $\begin{array}{l}\text { Conversa em inglês entre professora e } \\
\text { alunos sobre eleições (Is voting } \\
\text { elective or mandatory?; In Brazil, } \\
\text { which representatives do we vote } \\
\text { for?). }\end{array}$ & Elections & $\begin{array}{l}3^{\circ} \text { ano } \\
\text { do ensino médio }\end{array}$ \\
\hline Fragmento 7 & $\begin{array}{l}\text { Conversa em inglês entre professora e } \\
\text { alunos em trabalho com pré-leitura e a } \\
\text { condução do enunciado da atividade. }\end{array}$ & Elections & $\begin{array}{l}3^{\circ} \text { ano } \\
\text { do ensino médio }\end{array}$ \\
\hline Fragmento 8 & $\begin{array}{l}\text { Condução de uma atividade de leitura } \\
\text { e sua correção. A atividade requer a } \\
\text { identificação de informações no texto. }\end{array}$ & Elections & $\begin{array}{l}3^{\circ} \text { ano } \\
\text { do ensino médio }\end{array}$ \\
\hline
\end{tabular}

3 - Especificação do evento interativo, da temática e da turma em cada fragmento do DVD.

Como já mencionado, cada fragmento de aula foi comentado pelas professoras autoras do DVD, cabendo a cada uma comentar quatro fragmentos. As análises foram roteirizadas e gravadas em estúdio para acompanhar cada um dos fragmentos de aula. Elas abordaram:

a) Fatores relacionados à aprendizagem/ aquisição de língua estrangeira, como a negociação de significados, a correção implícita (recast), a exposição do aluno ao insumo compreensível, o tipo de insumo, ofeedback e o foco na forma (LONG; ROBINSON, 1998);

b) Procedimentos metodológicos favoráveis à participação dos alunos (legitimação de fala, questionamentos, chamadas para a reflexão);

c) O uso de recursos pedagógicos (quadro);

d) Os objetivos de aprendizagem (produção e compreensão oral).

Os conteúdos das análises estão especificados no quadro a seguir: 


\begin{tabular}{|c|c|}
\hline & Conteúdos das análises \\
\hline Fragmento 1 & $\begin{array}{l}\text { Negociação de significados, legitimação da fala do aluno e correção } \\
\text { implícita (recast). }\end{array}$ \\
\hline Fragmento 2 & Forma de conduzir o entendimento do enunciado de uma atividade. \\
\hline Fragmento 3 & Erros de fala da professora e falta de feedback ao aluno. \\
\hline Fragmento 4 & $\begin{array}{l}\text { Inglês como meio de instrução, legitimação da voz do aluno, foco na } \\
\text { forma e as incertezas do professor. }\end{array}$ \\
\hline Fragmento 5 & Legitimação da fala do aluno e o foco no código linguístico. \\
\hline Fragmento 6 & $\begin{array}{l}\text { Inglês como meio de instrução, negociação de significados, uso do } \\
\text { quadro e legitimação da fala do aluno. }\end{array}$ \\
\hline Fragmento 7 & Tom dialogado da aula, o uso de tradução e negociação de significados. \\
\hline Fragmento 8 & $\begin{array}{l}\text { Forma de conduzir o entendimento do enunciado de uma atividade, o } \\
\text { posicionamento da professora com relação à produção oral dos alunos e a } \\
\text { forma de correção. }\end{array}$ \\
\hline
\end{tabular}

4 - O foco de análise em cada um dos fragmentos do DVD.

A versão final do DVD foi reproduzida em 500 cópias, as quais foram doadas à Secretaria do Estado de Educação de Santa Catarina para a sua distribuição gratuita aos professores de Inglês.

\section{Concepções de aprendizagem docente na mídia proposta}

A produção do DVD partiu das seguintes premissas:

1) O conhecimento pedagógico do professor pode ser aprimorado com a ajuda da tecnologia audiovisual. Nesse sentido, o uso dessa tecnologia não precisa estar exclusivamente a serviço do ensino do professor, mas também de sua aprendizagem para favorecer o seu desenvolvimento profissional e a qualidade de sua docência;

2) A aprendizagem docente é significativa quando o professor reflete sobre ações situadas, contextos de ensino que refletem genuinamente o seu ambiente de trabalho (NÓVOA, 2009; THERRIEN; CARVALHO, 2009). Segundo Nóvoa (2009), a formação de professores deve ser construída dentro da profissão e, por essa razão, as práticas pedagógicas devem ser investidas do ponto de vista teórico e metodológico, dando origem à construção (e desenvolvimento) do conhecimento profissional docente. Esse movimento, que parte da prática para a teoria, busca ser o inverso da tradição formativa docente, que é calcada na aplicação de teorias e nas referências externas ditando a prática pedagógica. 
Na mesma linha de raciocínio, Therrien e Carvalho (2009, p. 130-131) discutem a racionalidade pedagógica, entendida "como concepção ou conjunto de saberes que o professor constrói e articula continuamente acerca das categorias centrais do seu trabalho docente". Essa racionalidade pode ser construída através de abordagens desenvolvidas a partir da ação situada em contextos de interação e de intersubjetividade. Nesse sentido, pressupõe-se que o desenvolvimento docente pode se beneficiar da observação de aulas e da análise sobre elas;

3) A observação de fragmentos de aulas conduzidas em contextos de atuação do professor de língua estrangeira pode favorecer a teorização da prática, isto é, a construção de conhecimentos a partir da prática assistida e da sua análise (NÓVOA, 2009; KUMARAVADIVELU, 1994 - principled pragmatism; PRABHU, 1990 - sense of plausibility). É o que propõe o DVD Sala de Aula Comentada, que busca favorecer a aprendizagem docente pela observação e pelo entendimento das tomadas de decisão do professor na interação com seus alunos. A observação é, portanto, valorizada como método de reflexão.

4) $\mathrm{O}$ conhecimento pedagógico pode se valer não somente da reflexão baseada nos problemas que surgem na prática cotidiana dos profissionais (SHÖN, 2000), mas também da visualização de ações e fazeres que possam ser interpretados como positivos.

\section{Conclusão}

Este artigo buscou descrever uma experiência de produção de um DVD para o aprimoramento do conhecimento pedagógico do professor de língua inglesa, bem como as concepções teóricas e metodológicas adotadas para a sua produção. O DVD contem reproduções de eventos reais de sala de aula conduzidos em contextos de escola básica, cada qual acompanhado de comentários analíticos, visando problematizar, trazer soluções e apontar estratégias acertadas de ensino. A aprendizagem docente é favorecida por meio da observação de fragmentos de aula e da reflexão sobre as interações apresentadas entre professora e aluno(s), com a perspectiva crítica de especialistas na área.

Embora a mídia apresentada tenha o objetivo de aprimorar o conhecimento pedagógico do professor de inglês, nenhum estudo foi ainda conduzido para investigar os seus efeitos na prática de ensino do professor, uma questão que mereceria ser examinada, assim como a percepção dos professores sobre o potencial dessa mídia.

\section{Referências}

GATCONTON, E. Investigating experienced ESL teachers' pedagogical knowledge. The Modern Language Journal. v. 83, p. 35-50, 1999.

KUMARAVADIVELU, B. The postmethod condition: (E)merging strategies for second/ foreign language teaching. TESOL Quarterly, v. 28, n. 1, p. 27-48, 1994. 
LONG, M. H.; ROBINSON, P. Focus on form. Theory, research, and practice. In: DOUGHTY, C.; WILLIAMS, J. (Orgs.). Focus on form in classroom second language acquisition. Cambridge: CUP, 1998, p. 15-41.

NÓVOA, A. Professores: Imagens do futuro presente. Educa: Lisboa, 2009. Disponível em: $<$ http://www.etepb.com.br/arq_news/2012texto_professores_imagens_do_futuro_presente.pdf $>$. Acesso em: 24 jan. 2012.

PRABHU, N. S. There is no best method - Why? TESOL Quarterly, v. 24, n. 2, p. 161-176, 1990.

SHÖN, D. A. Educando o profissional reflexivo: Um novo design para o ensino e a aprendizagem. São Paulo: Artes Médicas, 2000.

THERRIEN, J.; CARVALHO, A. D. F. O professor no trabalho: Epistemologia da prática e ação/ cognição situada - elementos para a análise da práxis pedagógica. Revista Brasileira de Formação de Professores, v. 1, n.1, p.129-147, 2009. 